\title{
Andrew Fielding Huxley (1917-2012)
}

\section{Biophysicist who showed how nerves carry electrical signals and muscles contract.}

A ndrew Fielding Huxley made three crucial discoveries in physiology and biophysics. For establishing how ions carry electrical signals in nerves, he shared the Nobel prize with Alan Hodgkin and John Eccles in 1963. He also described how molecular motors enable muscles to shorten and exert force and how electrical activity triggers the contraction of muscle fibres.

Huxley died on 30 May at the age of 94. He grew up in Cambridge, UK, in a prominent academic and literary dynasty. To his immense pride, his grandfather, the anatomist Thomas Henry Huxley, 'Darwin's bulldog', had defended Charles Darwin in early debates about evolution. Andrew's half-brothers were Brave New World author Aldous and evolutionary biologist Julian Huxley.

Andrew Huxley obtained his undergraduate degree in physiology from the University of Cambridge, UK, in 1938. His research was interrupted by the Second World War, during which he applied himself to developing radar and gunnery. After the war, he did not bother with a doctorate: it is said that no one felt competent to serve on his awarding committee. But to his students, who knew him as Prof, Huxley's formidable intellect was made less daunting by his warmth, modesty and enthusiasm. His marriage to the delightful Richenda Pease resulted in six children.

Huxley first encountered the squid giant axon in 1939, working with Hodgkin at the Laboratory of the Marine Biological Association in Plymouth, UK, and resumed work on it after the war. This large nerve fibre provided the keys to understanding the electrical activity that excites biological cells, which had been a mystery since the eighteenth-century experiments of Luigi Galvani and Alessandro Volta in muscle excitability and electricity.

Huxley and Hodgkin's collaboration with biophysicist Bernard Katz yielded the sodium theory of the action potential. Published in 1952, this work showed that the axon membrane can, within a millisecond, switch from being permeable to potassium ions to being permeable to sodium ions instead, causing a voltage spike termed the action potential. The inflow of sodium ions initiates and reinforces the impulse as it carries a signal along the axon, from a fingertip to the spinal cord to the brain, for example.
Hodgkin and Huxley measured the kinetics and voltage dependence of these permeability changes and expressed them as equations, which Huxley evaluated using a mechanical calculator. Their formulation still provides the framework for our understanding of electrical activity in the

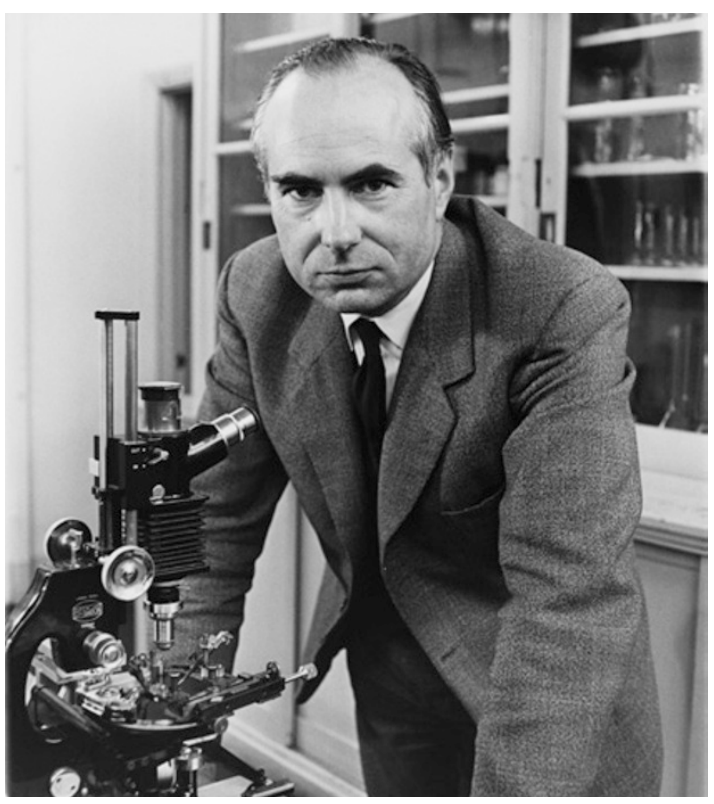

nervous system and throughout the body. It presaged the discovery of the sodium and potassium channels central to brain activity and is also the basis for our understanding of the heartbeat, cardiac arrhythmias and many drugs.

Huxley turned next to muscle contraction, reviving a boyhood interest in mechanical devices and optical microscopy. He built a two-beam interference microscope and used it to discover how muscle produces force and shortens, and how electrical signals activate contraction.

In 1954, with Rolf Niedergerke (who also died this year), Huxley published the 'sliding-filament' hypothesis, which showed that myosin and actin protein filaments slide relative to one other as muscles shorten. The filaments are propelled by myosin molecular motors that 'walk' along the actin, attaching and detaching. Huxley's ideas underpin a host of molecular motors and cell-motility mechanisms, which are important in the cardiovascular and neurological systems and cancer.

Huxley's second pivotal microscopic observation, published in 1958, showed how voltage differences across the surface membranes of muscle fibres are transmitted deep within the cell along transverse tubules spaced periodically along the fibre. We now know that the signal stimulates the release of calcium ions, which activate the contraction system. Hundreds of similar signal cascades that result in the inward spread of electrical or hormonal excitation have since been discovered in endocrinology, neuroscience and immunology.

Huxley held prominent academic positions - as head of physiology at University College London (beginning in 1960), president of the Royal Society (1980-85), president of the British Science Association (1976-77) and master of Trinity College, Cambridge (1984-90). His management style was meticulous, and at times considered too exacting.

Many of his concerns resonate today: the funding of research and faculty in times of scarcity, industry-university partnerships, the free dissemination of results and England's role in international scientific programmes. Like his grandfather, he spoke strongly for the evaluation of scientific results solely on their merits, and he opposed the suppression of studies on the basis of their unpopularity or for political contingencies.

As postdoctoral fellows in Huxley's laboratory, we had much contact with Prof over the years, although we did not share many publications. He had a strict attitude towards authorship and listed himself only if his contribution was high, but he was always interested and helpful. He had little patience for those who were unprepared, but for those who were, his views were a gold mine.

Andrew Huxley inspired generations of scientists with his careful, imaginative technique and his clear vision. His uses of new instrumentation and the interplay between experimental tests and quantitative models are ideals to be emulated. -

Yale E. Goldman and Clara FranziniArmstrong are at the Pennsylvania Muscle Institute, and Clay M. Armstrong is in the Department of Physiology, at the Perelman School of Medicine, University of Pennsylvania, Philadelphia, Pennsylvania 19104, USA. e-mail:goldmany@yahoo.com 